\title{
Observed and Simulated Upper-Tropospheric Water Vapor Feedback
}

\author{
A. Gettelman \\ National Center for Atmospheric Research,* Boulder, Colorado \\ Q. FU \\ University of Washington, Seattle, Washington
}

(Manuscript received 12 July 2007, in final form 26 November 2007)

\begin{abstract}
Satellite measurements from the Atmospheric Infrared Sounder (AIRS) in the upper troposphere over $4.5 \mathrm{yr}$ are used to assess the covariation of upper-tropospheric humidity and temperature with surface temperatures, which can be used to constrain the upper-tropospheric moistening due to the water vapor feedback. Results are compared to simulations from a general circulation model, the NCAR Community Atmosphere Model (CAM), to see if the model can reproduce the variations. Results indicate that the upper troposphere maintains nearly constant relative humidity for observed perturbations to ocean surface temperatures over the observed period, with increases in temperature $\sim 1.5$ times the changes at the surface, and corresponding increases in water vapor (specific humidity) of $10 \%-25 \%{ }^{\circ} \mathrm{C}^{-1}$. Increases in water vapor are largest at pressures below $400 \mathrm{hPa}$, but they have a double peak structure. Simulations reproduce these changes quantitatively and qualitatively. Agreement is best when the model is sorted for satellite sampling thresholds. This indicates that the model reproduces the moistening associated with the observed uppertropospheric water vapor feedback. The results are not qualitatively sensitive to model resolution or model physics.
\end{abstract}

\section{Introduction}

The largest uncertainty in predicting the future state of the atmosphere lies in properly estimating the internal changes to the climate system in response to a radiative perturbation (Cess et al. 1989; Cess 2005). The impact of these internal changes, commonly called feedbacks on the climate system, can be as large as the primary forcing signal. Perhaps the most important feedback in the earth's climate system is the climate feedback due to upper-tropospheric water vapor $\left(\mathrm{H}_{2} \mathrm{O}\right)$, whereby a change in climate state changes water vapor, which is the primary greenhouse gas (Held and Soden 2000). This increase in water vapor then

* The National Center for Atmospheric Research is sponsored by the National Science Foundation.

Corresponding author address: A. Gettelman, National Center for Atmospheric Research, 1850 Table Mesa Dr., Boulder, CO 80305.

E-mail: andrew@ucar.edu further changes the climate state by enhancing the greenhouse effect of water vapor. This is often simply called the "water vapor feedback." The water vapor feedback has generally been thought to be positive, with most atmospheric models maintaining constant relative humidity with increasing temperatures throughout the tropical tropospheric column. This implies increases in specific humidity.

In the last decade or so there has been some debate on the water vapor feedback, with some authors suggesting that the relationship between increasing temperature at the surface and upper-tropospheric humidity may be negative (Lindzen 1990). However, most recent studies indicate that the water vapor feedback is positive (Held and Soden 2000), including recent work using satellite humidity observations (Minschwaner and Dessler 2004) and climate models compared to satellite temperature and humidity observations (Soden et al. 2005).

This study will build upon previous estimates of the water vapor feedback, by focusing on the observed response of upper-tropospheric temperature and humidity (specific and relative humidity) to changes in surface 
temperatures, particularly ocean temperatures. Similar efforts have been performed before (see below), but this study will use new high vertical resolution satellite measurements and compare them to an atmospheric general circulation model (GCM) at similar resolution.

The water vapor feedback arises largely from the tropics where there is a nearly moist adiabatic profile. If the profile stays moist adiabatic in response to surface temperature changes, and if the relative humidity ( $\mathrm{RH})$ is unchanged because of the supply of moisture from the oceans and deep convection to the upper troposphere, then the upper-tropospheric specific humidity will increase. The tropical atmosphere appears to maintain a nearly moist adiabatic profile (Neelin and Zeng 2000), because gravity waves efficiently spread heat over an almost infinitely large Rossby radius (a result of the small Coriolis parameter). Waves and mixing maintain a horizontally uniform temperature profile over the entire tropics. This temperature profile is determined by moist adiabatic lifting of near-surface air over warm moist parts of the tropics (e.g., Held and Hou 1980; Bretherton and Sobel 2002). Thus the maintenance of this moist adiabatic profile is accomplished by deep convection along with an efficient dynamic stratified adjustment. We test this hypothesis as part of the analysis in this work.

If the surface temperature of the tropics were to change, the hypothesis is that the atmosphere would relax to a warmer moist adiabat. This is consistent with a large positive water vapor feedback at upper levels (constant relative humidity). It implies increases in water vapor throughout the profile, increasing the total atmospheric absorption (the total atmospheric greenhouse effect). It may also change clouds and their radiative forcing of climate, so-called cloud feedbacks (Bony et al. 2006).

The goal of this work is a better understanding of specific feedback processes using better statistics and vertical resolution than has been possible before. We will compare satellite data over a short $(4.5 \mathrm{yr})$ time record to a climate model at similar space and time resolution and examine the robustness of results with several model simulations. The hypothesis we seek to test is whether water vapor in the model responds to changes in surface temperatures in a manner similar to the observations. This can be viewed as a necessary but not sufficient condition for the model to reproduce the upper-tropospheric water vapor feedback caused by external forcings such as anthropogenic greenhouse gas emissions.

Section 2 describes the methodology. Results are contained in section 3. Conclusions are in section 4 .

\section{Methodology}

In this work we will use profile data for humidity and temperature from the Atmospheric Infrared Sounder (AIRS) to analyze how the atmosphere (mostly the upper troposphere) responds to changes in the underlying surface temperature. We equate this variation with a measure of the first part of the water vapor feedback: a change in climate state changes water vapor and its greenhouse effect. We take the approach that using high spatiotemporal data can allow us to explore many different time scales. Most work analyzing feedbacks has looked at annual or interannual time scales, such as the impact of volcanic eruptions (Soden et al. 2002), the El Niño-Southern Oscillation (Blankenship and Wilheit 2001), or a single month or two of data (Ramanathan et al. 1989). Here we will use monthly data over four annual cycles to try to better understand the feedback processes.

A fundamental question is over what space and time scales the feedback operates. If indeed the uppertropospheric water vapor feedback is related to the coupling between the surface and the upper troposphere through convection, this is a fast process and the feedback might operate rapidly (on space scales of $100 \mathrm{~s}$ of $\mathrm{km}$ and time scales of days). If the feedback is a tropical mean response, this implies a strong coupling between moist and dry regions through subsidence drying (Hartmann and Larson 2002) and the general (Hadley) circulation, then we might assume that monthly or seasonal averages over the entire tropics might be more appropriate. Since the adjustment is relatively rapid in the tropics, the coupling of the mean response of the upper troposphere to the surface is likely to be on the order of a month or so. In this work we will focus on monthly and tropical averaged scales. We detail the approach below, and then we describe the data and model used.

\section{a. Approach}

We will analyze the water vapor feedback by looking at the covariability of tropical averaged sea surface temperatures (SSTs) and upper-tropospheric temperature and humidity (specific and relative). We define the tropics here as latitudes within $30^{\circ}$ of the equator, to include the subtropical subsidence regions. For tropical averages, the transport and adjustment time may be longer than a month, since the radiative relaxation time in the upper troposphere approaches 30 days (Hartmann and Larson 2002). So a 1-month lag will be applied to upper-tropospheric data in the results presented here. 
We will examine the sensitivity of the results in particular to the sampling bias of AIRS (see below). Since AIRS is a nadir IR sounder, AIRS cannot retrieve profiles of temperature and humidity in the presence of more than $70 \%$ cloud cover. So we will sort the model output by a similar criterion, and use tropical averages from the simulations that include only those points with cloud cover (total cloud in a column) of less than $70 \%$. We will perform this sorting on daily data and monthly averages to explore differences.

We will also use several different model runs to explore how sensitive the results are to various factors. We will use different time periods, attempting first to match the AIRS period, and then look at a longer period. We will also explore the sensitivity of the results to formulations of the model resolution and moist physics parameterizations.

\section{b. Observations}

The AIRS instrument on Aqua is used for retrievals of temperature, surface temperature, and specific humidity (Susskind et al. 2003, 2006). The analysis will use 54 months of AIRS data from September 2002 through February 2007.

The 2378 independent channels on AIRS permit retrieval of an entire profile in the presence of up to $70 \%$ cloud fraction over the AIRS footprint. We use AIRS level 2 data retrievals (version 4.0). AIRS data are processed into a daily gridded product as described by Gettelman et al. (2006a). We use standard version 4 retrieved profiles (level 2) obtained from the National Aeronautics and Space Administration (NASA) Goddard Space Flight Center (GSFC) Distributed Active Archive Center (DAAC) and bin them to a $1^{\circ} \times 1^{\circ}$ horizontal grid. Relative humidity is constructed as described by Gettelman et al. (2006a,b) from the individual profile temperature and water vapor mixing ratios. AIRS data have been validated in the upper troposphere by Gettelman et al. (2004) against aircraft data, and by Divakarla et al. (2006) against radiosonde data globally. In all cases, single profile uncertainties in temperature are generally around $1 \mathrm{~K}$, and uncertainty in specific humidity is around $20 \%$, with no significant bias. In summary, AIRS data well represent uppertropospheric temperature and humidity when compared to radiosondes or aircraft instruments.

\section{c. CAM description}

For comparison to observations we will use simulations of the National Center for Atmospheric Research (NCAR) Community Atmosphere Model version 3
(CAM), described by Collins et al. (2006). The model is run using $1^{\circ} \times 1.25^{\circ}$ horizontal resolution and 26 levels in the vertical. Gettelman et al. (2006a) show that CAM can reproduce the climatology of relative humidity in the troposphere, with a slight moist bias relative to the observations, which yields differences in the global energy balance of $\sim 1 \mathrm{~W} \mathrm{~m}^{-2}$. Intraseasonal variability of humidity in the tropical upper troposphere is not as well reproduced, likely due to problems in simulating deep convection. Thus it is an open question of whether the model can reproduce some of the feedback mechanisms that depend on convective coupling of the surface to the upper troposphere.

We use several different runs to try to understand the sensitivity of the model results to time period or model configuration. For the most detailed comparison with observations, we run the model with surface temperatures taken from observations during 2001-04 (36 months). Model SSTs may be slightly different from the data, but represent a partially overlapping period. We expect some scatter, but the entire 2001-07 period does not feature strong expressions of tropical modes [such as the El Niño-Southern Oscillation (ENSO)] so we do not expect this to affect the results. Daily average model output is used for comparison to the satellite observations (binned for all overpasses within $24 \mathrm{~h}$ ). This model output is then filtered for locations where the average daily or monthly cloud fraction is less than 0.7, the threshold for successful AIRS retrievals. We compare the effect of averaging and sorting the model output on the results below.

In addition, we examine several different simulations with different versions of CAM to see if these results are robust for different configurations and formulations of the model. These runs also use different sea surface temperatures, so we will be comparing against a completely different time period than the observations. We will test four additional model runs. First is the base case model presented above, but run for a longer time period, denoted "CAM." Second, we evaluate a run at lower horizontal resolution $\left(2^{\circ} \times 2.5^{\circ}\right.$ latitude and longitude) denoted " $2 x$." Third is a run with supersaturation permitted in the ice phase as described by Gettelman and Kinnison (2007), denoted "SSAT," and fourth is a simulation with a more detailed microphysics parameterization for stratiform precipitation described by Morrison and Gettelman (2008) and Gettelman et al. (2008), denoted "MICROP." This suite of runs allows us some insight into whether the covariability is strongly sensitive to surface boundary conditions, resolution, or different representations of the model moist physics important for the upper troposphere. 

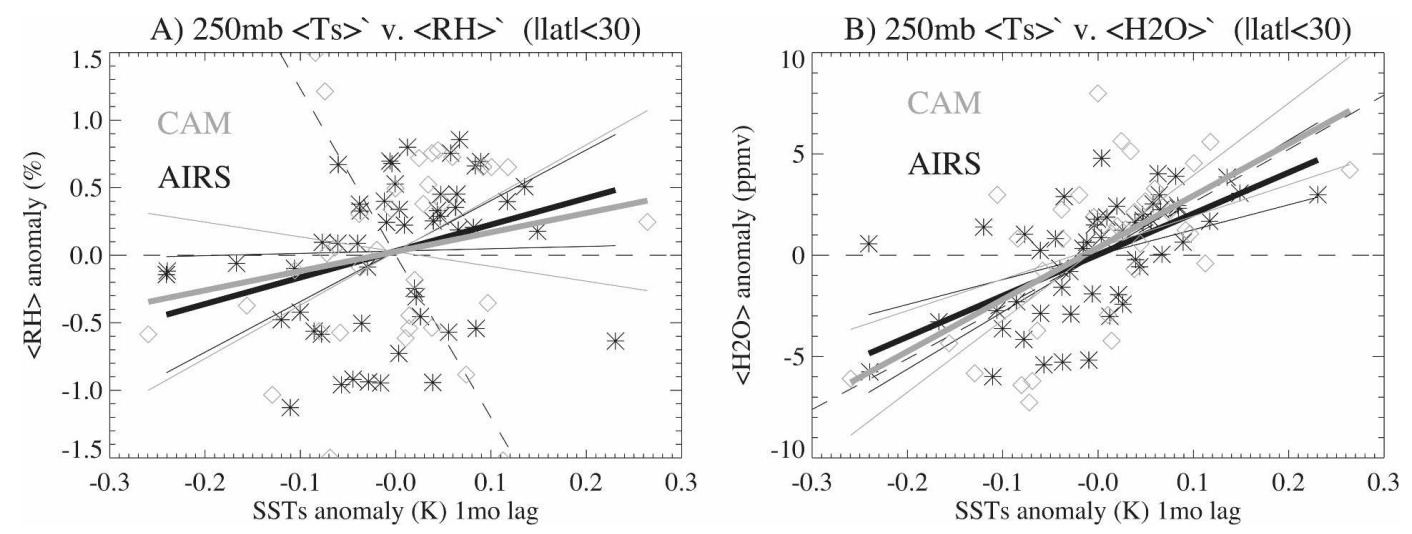

FIG. 1. (a) RH and (b) specific humidity $(Q)$ from both AIRS data (black asterisks) and CAM simulation (gray diamonds). Thick lines illustrate bootstrap fits from AIRS (black) and CAM (gray), and thin lines are \pm two std dev $(2 \sigma)$ from the linear fit for AIRS and CAM. The thin dashed lines represent constant relative and specific humidity as a function of surface temperature as described in the text.

\section{Results}

We focus the results on the covariation of tropically averaged upper-tropospheric humidity and temperature with underlying surface temperatures. We construct tropical means and anomalies by removing the mean annual cycle.

The basic covariation of $\mathrm{RH}$ and $\mathrm{H}_{2} \mathrm{O}$ is illustrated in Fig. 1. Figure 1 shows 54 months of deseasonalized, monthly anomalies of RH (Fig. 1a) and specific humidity (Fig. 1b) from both AIRS data (black asterisks) and 36 months of CAM simulation (gray diamonds). Only CAM points with a cloud fraction less than $70 \%$ (sorted daily) are included in the average to approximate the locations the satellite would see. Each point represents a tropical average of temperatures above the ocean surface and relative humidity (Fig. 1a) or specific humidity (water vapor) (Fig. 1b) at $250 \mathrm{hPa}$ in the upper troposphere. A 1-month lag has been applied to the water fields in the upper troposphere. This lag allows the distribution of a response in one region due to convection to propagate throughout the tropics, and is approximately the time scale for radiative relaxation in the upper troposphere. Such a lag has also been used by Minschwaner and Dessler (2004). The lag reduces scatter in the analysis, but the significance of the conclusions is not changed if no lag is used.

Thick lines illustrate bootstrap fits (Efron and Tibshirani 1993), and thin lines are \pm two standard deviations $(2 \sigma)$ from the linear fit for AIRS (black lines) and CAM (gray lines). Where the thin lines straddle the zero line, the slope is not statistically different from zero (at the $2 \sigma$ or $\sim 95 \%$ level). The thin dashed lines represent lines of constant relative and specific humidity for a given change in upper-tropospheric tempera- ture. Constant relative humidity as a function of local temperature is identically a horizontal line at zero (thin dashed gray line in Fig. 1a), but a change in temperature for constant specific humidity will change RH dramatically (increasing $\mathrm{RH}$ as temperature cools and decreasing it as temperature warms), shown as a sloping thin dashed line in Fig. 1a.

Figure 1a has considerable scatter, but in general, there is little significant change of $250-\mathrm{hPa}$ relative humidity anomalies with anomalies in the previous month's surface temperature. The slope is not significantly different than zero in either AIRS observations $\left(1.9 \pm 1.9 \% \mathrm{RH}{ }^{\circ} \mathrm{C}^{-1}\right)$ or CAM $(1.4 \pm 2.8 \%$ $\left.\mathrm{RH}{ }^{\circ} \mathrm{C}^{-1}\right)$.

The situation for specific humidity in Fig. 1b indicates less scatter, and is a more fundamental measurement from AIRS (which retrieves specific humidity and temperature separately). In Fig. 1b, it is clear that 250$\mathrm{hPa}$ specific humidity increases with increasing averaged surface temperature in both AIRS observations and CAM simulations. At $250 \mathrm{hPa}$ this slope is $20 \pm 8$ ppmv ${ }^{\circ} \mathrm{C}^{-1}$ for AIRS and $26 \pm 11 \mathrm{ppmv}^{\circ} \mathrm{C}^{-1}$ for CAM. This is nearly $20 \%$ of background specific humidity per degree Celsius at $250 \mathrm{hPa}$.

The observations and simulations indicate that specific humidity increases with surface temperatures (Fig. $1 b)$. The increase is nearly identical to that required to maintain constant relative humidity (the sloping dashed line in Fig. 1b) for changes in upper-tropospheric temperature. There is some uncertainty in this constant $\mathrm{RH}$ line, since it depends on calculations of saturation vapor mixing ratio that are nonlinear, and the temperature used is a layer (200-250 hPa) average.

An examination of similar relationships between the temperature anomalies in the upper troposphere and 


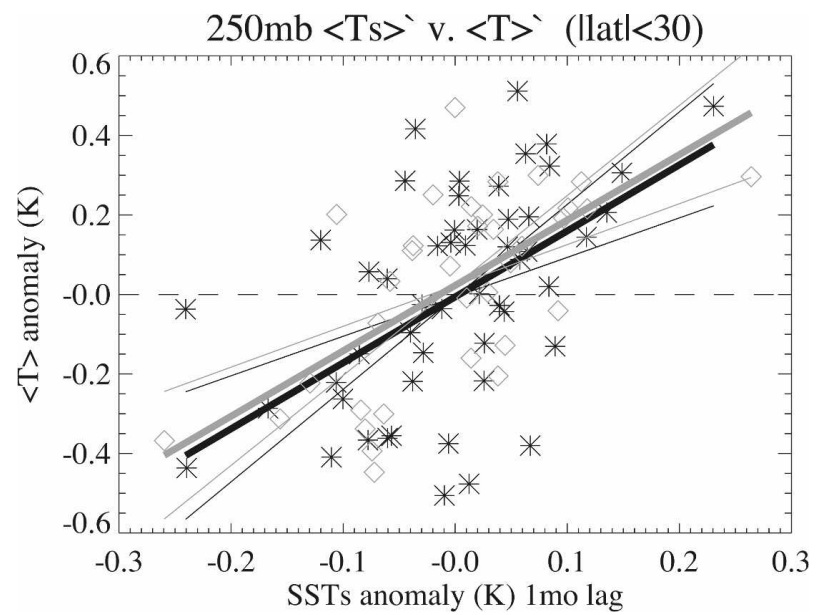

FIG. 2. Same as Fig. 1, but for surface temperature vs $250-\mathrm{hPa}$ monthly mean deseasonalized temperature anomalies over $\pm 30^{\circ}$ latitude.

the surface temperature is illustrated in Fig. 2. CAM temperatures have also been filtered for those points with cloud fraction less than $70 \%$ to mimic the AIRS sampling. Figure 2 indicates that for both AIRS observations and the CAM simulations, 250-hPa temperatures increase with increasing average surface temperatures, with a slope of $1.7 \pm 0.7^{\circ} \mathrm{C}^{\circ} \mathrm{C}^{-1}$ for AIRS (upper-tropospheric temperatures increase more than surface temperatures). CAM is very similar at $1.7 \pm$ $0.6^{\circ} \mathrm{C}^{\circ} \mathrm{C}^{-1}$. This value is similar to the temperature slope expected from moist adiabatic adjustment in the tropics. The slope is similar to results from Sun and Oort (1995) and Santer et al. (2005).

As noted above, one of the real benefits of AIRS data over previous sensors is the vertical resolution.
Figure 3 exploits this resolution by plotting the slope of the line and the confidence interval from Fig. 1 for water vapor and Fig. 2 for temperature at each level. The sort by cloud fraction each day as performed in Figs. 1 and 2 is illustrated in green. The 250-hPa level in Figs. 1 and 2 is noted as a dashed line. All lines are from the same model run. As in Fig. 1 at $250 \mathrm{hPa}$, there is little significant change in relative humidity for changes in SST at most levels, and RH appears to be generally constant with changes to SST. There is more vertical structure to the simulations than observations. This might be due to the $2-3-\mathrm{km}$ vertical resolution of AIRS in the upper troposphere.

Both AIRS and CAM show increasing temperature change with height (Fig. 3b), broadly consistent with a moist adiabatic assumption, and similar to the vertical structure of temperature changes noted by Santer et al. (2005) in radiosonde temperature soundings and model simulations. The changes are significant at all levels, and the model is not significantly different from the AIRS data, at $1^{\circ}-2^{\circ} \mathrm{C}^{\circ} \mathrm{C}^{-1}$.

Figure $3 \mathrm{c}$ illustrates the percent change in water vapor with increasing surface temperature. As with temperature, there are increases in specific humidity at all heights in both the AIRS observations and the CAM simulations. The combination of increases in temperature and humidity need not keep relative humidity exactly constant as seen in Figs. 1 and 3a. Also, CAM shows slightly larger sensitivity, though at most levels the slopes are not statistically different from AIRS. Despite large scatter seen in Fig. 1, the changes in specific humidity in Fig. 3c are significantly different than zero when sorted by cloud fraction daily at all levels. The slope of nearly $25 \% \mathrm{H}_{2} \mathrm{O}{ }^{\circ} \mathrm{C}^{-1}$ is large. Observed sur-
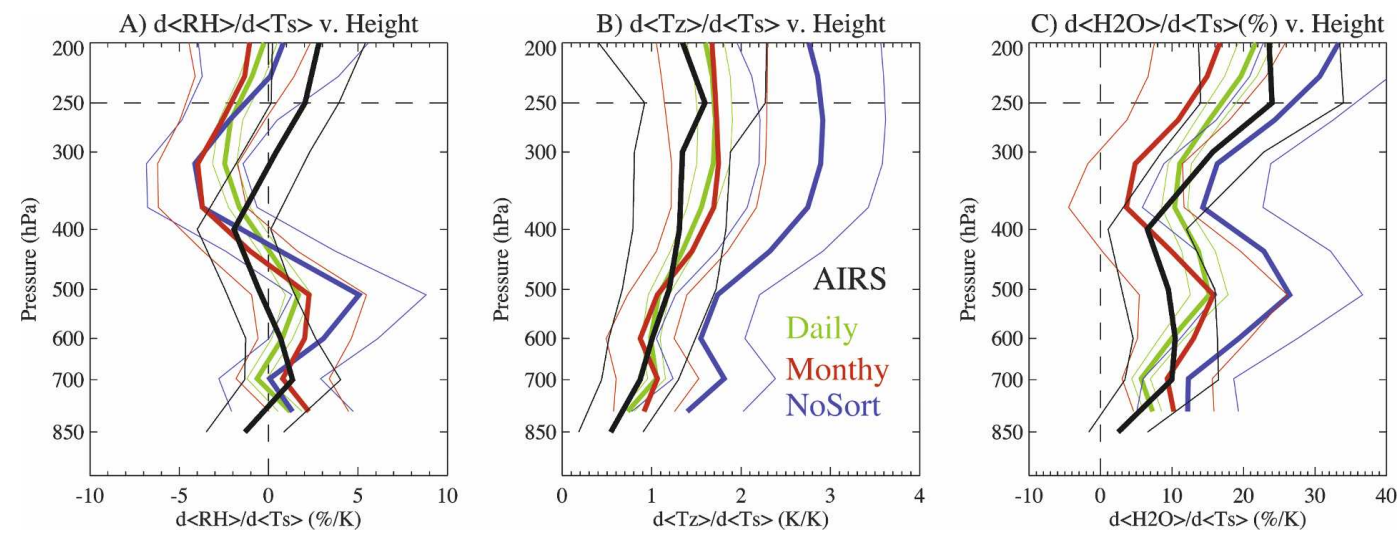

FIG. 3. The (a) $d \mathrm{RH}(z) / d \mathrm{Ts}$, (b) $d T(z) / d \mathrm{Ts}$, and (c) $d \mathrm{H}_{2} \mathrm{O}(z) / d \mathrm{Ts}\left(\mathrm{dH}_{2} \mathrm{O}\right.$ in percent for specific humidity) as a function of height for AIRS (black lines) and CAM (colored lines). CAM sorted for cloud fraction daily (green), monthly (red), and no sorting (blue). The horizontal line shows the 250 -hPa level, and the vertical line is the zero line. Thick lines are the mean, and thin lines are $\pm 2 \sigma$ from the mean. 

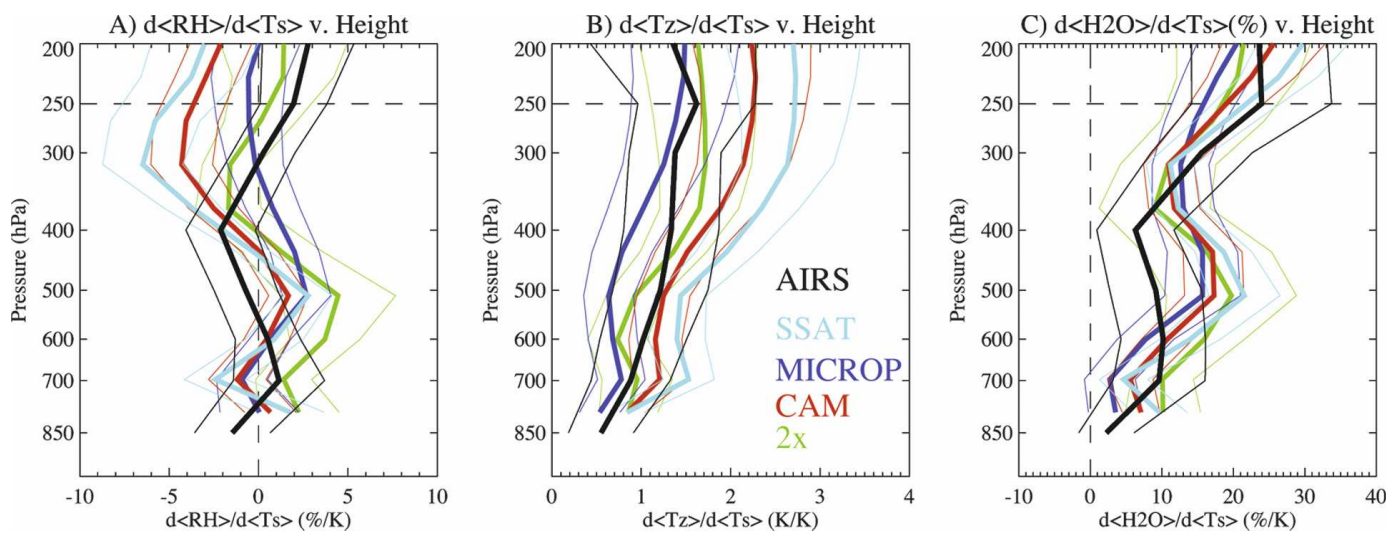

FIG. 4. Same as Fig. 3, but for different simulations, sorted monthly by clouds. Simulations are base case (red: $\mathrm{CAM}$ ). Base case $1.9^{\circ} \times 2.5^{\circ}$ horizontal resolution (green: $2 \mathrm{x}$ ), supersaturation for ice (light blue: SSAT), and new stratiform microphysics (dark blue: MICROP). AIRS observations are in black.

face temperature anomalies are $\pm 0.1 \mathrm{~K}$, so $\mathrm{H}_{2} \mathrm{O}$ changes over this record are typically $5 \%$.

Figure 3 also illustrates the effect of sorting the model results for cloud fraction. In general, if the simulation is not sorted by locations where cloud fraction is less than $70 \%$ (NoSort), the temperature and water vapor changes are larger than observed (Figs. $3 \mathrm{~b}$ and 3c), leaving RH (Fig. 3a) the same. In general, the results produced by sorting for cloud fraction by monthly averages of cloud, temperature, and humidity (monthly) produce results similar to the sort by daily average values (daily). The difference from the NoSort case makes sense since sorting for regions with significant cloudiness filters out the wettest and warmest regions (since deep convection supplies latent heat and water vapor).

Interestingly, both observations and simulations show a complex structure in the troposphere, with larger increases at $600 \mathrm{hPa}$ (AIRS) or $500 \mathrm{hPa}(\mathrm{CAM})$, or a minimum in changes at $400 \mathrm{hPa}$ and larger increases above at 250 or $200 \mathrm{hPa}$. This may be related to the structure of tropical convection, with shallow convection detraining at $600-500 \mathrm{hPa}$, and deep convection detraining at 250-200 $\mathrm{hPa}$. The increase in convection causes a peaked structure in the moistening. The structure is also seen less distinctly in the AIRS observations (perhaps due to $2-3-\mathrm{km}$ vertical resolution as noted). Note that Fig. $3 \mathrm{c}$ is in percent water vapor terms, so at upper levels the increase in mass or mixing ratio is small, but large in percent terms. The change is still important for radiation in this region, since by mass OLR is more sensitive to changes in upper-tropospheric water vapor.

Finally, we examine several different simulations with different versions of the CAM model to see if these results are robust for different configurations and formulations of the model. These runs also use different sea surface temperatures, so we will be comparing against a completely different time period than the observations. We will test four additional model runs described in section 2: (i) the base case model run for a longer time period (CAM), (ii) a run at lower $\left(2^{\circ} \times\right.$ $2.5^{\circ}$ ) horizontal resolution $(2 \mathrm{x})$, (iii) a run with supersaturation permitted in the ice phase (SSAT), and (iv) a simulation with a different microphysics parameterization for stratiform precipitation (MICROP). The CAM, MICROP, and SSAT runs use SSTs from 1978 to 1986 ( 9 yr), and the 2x run uses SSTs from 1978 to 2003 (26 yr).

The vertical structure of the covariability of $\mathrm{RH}$, temperature, and specific humidity in these simulations and AIRS observations is illustrated in Fig. 4. The AIRS observations (black line) are the same as in Fig. 3. All runs are sorted monthly for locations where cloud fraction is less than $70 \%$, which yields results similar to sorting daily (Fig. 3). For relative humidity (Fig. 4a), the model simulations show a tendency toward reduced RH at upper levels with warmer SSTs, and this is significantly different from zero in all but the MICROP (different stratiform microphysics) case. The response is larger than the response of the model over the shorter period noted in Fig. 3a.

For temperature, Fig. 4b, all runs show a similar structure, with larger increases seen for the base case (CAM) and supersaturation runs. The longer lowresolution run $(2 \mathrm{x})$ shows results very similar to AIRS observations, consistent with larger temperature increases with height than at the surface (consistent with a moist adiabatic profile).

For specific humidity, Fig. 4c, a similar structure is seen to that in Fig. 3c. All the models show increases in $\mathrm{H}_{2} \mathrm{O}$ in the upper troposphere, with the supersaturation 
case having slightly larger increases, particularly at pressures below $250 \mathrm{hPa}$. This is not surprising, given the enhancement in water vapor permitted by supersaturation. At upper levels, 300-200 hPa, the increase in specific humidity occurs despite decreases in RH. All the simulations also show a local minimum in the structure at $300-400 \mathrm{hPa}$, and maximum near $500 \mathrm{hPa}$. AIRS observations have a minimum at $400 \mathrm{hPa}$, and maximum from 600 to $700 \mathrm{hPa}$, which is not as clear. Thus the covariation of upper-level temperature and humidity with surface temperature is robust over various time periods, resolutions, and changes to model moist physical parameterizations.

\section{Conclusions}

In general, CAM simulations have similar variability of $\mathrm{RH}$, temperature, and $\mathrm{H}_{2} \mathrm{O}$ as AIRS observations in the upper troposphere. The covariation of uppertropospheric moisture and temperature with surface temperatures agrees better with AIRS observations when sorted by similar sampling criteria to AIRS. The simulations show some tendency for decreases in RH as surface temperature increases, largely due to larger increases in temperature than observed. This might simply be a function of the threshold value assumed for AIRS cloudiness: if AIRS is only able to retrieve when there is $60 \%$ cloudiness or less, for example, this would remove some of the wettest and warmest scenes from $\mathrm{CAM}$ and perhaps reduce the difference.

These results from AIRS and CAM simulations indicate that as surface temperatures increase, water vapor in the upper troposphere increases in observations to maintain nearly constant relative humidity. Thus the water vapor feedback is positive, and yields near constant upper-tropospheric RH. Note that RH can decrease even if specific humidity increases as a result of the nonlinear change of saturation vapor mixing ratio with temperature. The result is consistent with analysis by Soden et al. (2005) using a different model and satellite observations of humidity (from the Special Sensor Microwave Imager) and temperature (from the Microwave Sounding Unit and the High Resolution Infrared Radiometer Sensor), indicating that simulated uppertropospheric temperature response over the observed record was similar to observations and to a constant $\mathrm{RH}$ assumption. The result is also consistent with the results of Minschwaner and Dessler (2004). The increase in temperature scales is like a moist adiabat, with increases larger at higher altitudes, similar to Santer et al. (2005).

Results suggest a structure to the changes, with larger increases at higher altitudes (lower pressures) and a local peak in moistening at $400-600 \mathrm{hPa}$ in CAM and $700 \mathrm{hPa}$ in AIRS, or a relative minimum in moistening between these levels. This hints that perhaps the structure of convection in the tropics is changing, either through enhanced moistening at upper levels $(200 \mathrm{hPa})$ and enhanced subsidence below (300-400 hPa) or possibly through changes to midlevel convection $(500 \mathrm{hPa})$. This structure is an interesting subject for future study.

On balance, CAM simulated upper-tropospheric humidity and temperature appears to respond on monthly time scales similarly to observations from AIRS. If the coupling of the upper troposphere and the surface is occurring on these relatively fast time scales of a month or so, then these results enhance confidence that model water vapor responses to changes in the climate state are similar to observations and imply near-constant $\mathrm{RH}$ for small changes to mean ocean temperatures. This implies that the first part of the water vapor feedback, the change in upper-tropospheric humidity in response to changes in surface temperatures, is simulated correctly in CAM. These results provide enhanced confidence in the range of climate sensitivity in climate simulations, which are based on a positive uppertropospheric water vapor feedback. This is a necessary but not sufficient condition for trusting future climate projections from GCMs. Furthermore, the results hint at a vertical structure to the variations, which may help reveal the processes responsible. Further processoriented studies will be valuable in verifying that moistening affects climate and in understanding how clouds at various levels may change with changes to surface temperatures.

Acknowledgments. This work was performed under NASA EOS Grant NNG04GM23G to NCAR and UW-Seattle. Thanks to P. Duffy and G. Bala of LLNL and R. Neale of NCAR for assistance with CAM simulations.

\section{REFERENCES}

Blankenship, C. B., and T. T. Wilheit, 2001: SSM/T-2 measurements of regional changes in three-dimensional water vapor fields during ENSO events. J. Geophys. Res., 106 (D6), 52395254 .

Bony, S., and Coauthors, 2006: How well do we understand and evaluate climate change feedback processes? J. Climate, 19, 3445-3482.

Bretherton, C. S., and A. H. Sobel, 2002: A simple model of a convectively coupled Walker circulation using the weak temperature gradient approximation. J. Climate, 15, 2907-2920.

Cess, R. D., 2005: Water vapor feedback in climate models. Science, 310, 795-796.

- and Coauthors, 1989: Interpretation of cloud-climate feedback as produced by 14 atmospheric general circulation models. Science, 245, 513-516. 
Collins, W. D., and Coauthors, 2006: The formulation and atmospheric simulation of the Community Atmosphere Model version 3 (CAM3). J. Climate, 19, 2144-2161.

Divakarla, M. G., C. D. Barnet, M. D. Goldberg, L. M. McMillin, E. Maddy, W. Wolf, L. Zhou, and X. Liu, 2006: Validation of Atmospheric Infrared Sounder temperature and water vapor retrievals with matched radiosonde measurements and forecasts. J. Geophys. Res., 111, D09S15, doi:10.1029/ 2005JD006116.

Efron, B., and R. J. Tibshirani, 1993: An Introduction to the Bootstrap. Monographs on Statistics and Applied Probability, Vol. 57, Chapman and Hall, 436 pp.

Gettelman, A., and D. E. Kinnison, 2007: The global impact of supersaturation in a coupled chemistry-climate model. Atmos. Chem. Phys., 7, 1629-1643.

—, P. M. F. Forster, M. Fujiwara, Q. Fu, H. Vömel, L. K. Gohar, C. Johanson, and M. Ammerman, 2004: Radiation balance of the tropical tropopause layer. J. Geophys. Res., 109, D07103, doi:10.1029/2003JD004190.

—, W. D. Collins, E. J. Fetzer, F. W. Irion, A. Eldering, P. B. Duffy, and G. Bala, 2006a: Climatology of uppertropospheric relative humidity from the atmospheric infrared sounder and implications for climate. J. Climate, 19, 61046121.

— , V. P. Walden, L. M. Miloshevich, W. L. Roth, and B. Halter, 2006b: Relative humidity over Antarctica from radiosondes, satellites, and a general circulation model. J. Geophys. Res., 111, D09S13, doi:10.1029/2005JD006636.

- H. Morrison, and S. J. Ghan, 2008: A new two-moment bulk stratiform cloud microphysics scheme in the community atmosphere model (CAM3). Part II: Single-column and global results. J. Climate, 21, 3863-3882.

Hartmann, D. L., and K. Larson, 2002: An important constraint on tropical cloud-climate feedback. Geophys. Res. Lett., 29, 1951, doi:10.1029/2002GL015835.

Held, I. M., and A. Y. Hou, 1980: Nonlinear axially symmetric circulations in a nearly inviscid atmosphere. J. Atmos. Sci., 37, $515-533$
- and B. J. Soden, 2000: Water vapor feedback and global warming. Annu. Rev. Energy Environ., 25, 441-475.

Lindzen, R. S., 1990: Some coolness concerning global warming. Bull. Amer. Meteor. Soc., 71, 288-299.

Minschwaner, K., and A. E. Dessler, 2004: Water vapor feedback in the tropical upper troposphere: Model results and observations. J. Climate, 17, 1272-1282.

Morrison, H., and A. Gettelman, 2008: A new two-moment bulk stratiform cloud microphysics scheme in the community atmosphere model (CAM3). Part I: Description and numerical tests. J. Climate, 21, 3845-3862.

Neelin, J. D., and N. Zeng, 2000: A quasi-equilibrium tropical circulation model formulation. J. Atmos. Sci., 57, 1741-1766.

Ramanathan, V., R. D. Cess, E. F. Harrison, P. Minnis, B. R. Barkstrom, E. Ahmad, and D. Hartmann, 1989: Cloudradiative forcing and climate: Results from the Earth Radiation Budget Experiment. Science, 243, 57-63.

Santer, B. D., and Coauthors, 2005: Amplification of surface temperature trends and variability in the tropical atmosphere. Science, 309, 1551-1556, doi:10.1126/science.1114867.

Soden, B. J., R. T. Wetherald, G. L. Stenchikov, and A. Robock 2002: Global cooling after the eruption of Mount Pinatubo: A test of climate feedback by water vapor. Science, 296, 727730, doi:10.1126/science.296.5568.727.

—, D. L. Jackson, V. Ramaswamy, M. D. Schwarzkopf, and $X$. Huang, 2005: The radiative signature of upper tropospheric moistening. Science, 310, 841-844, doi:10.1126/science.1115602.

Sun, D.-Z., and A. H. Oort, 1995: Humidity-temperature relationships in the tropical troposphere. J. Climate, 8, 19741987.

Susskind, J., C. D. Barnet, and J. M. Blaisdell, 2003: Retrieval of atmospheric and surface parameters from AIRS/AMSU/ HSB data in the presence of clouds. IEEE Trans. Remote Sens., 41, 390-409.

- — - _ - L. Iredell, F. Keita, L. Kouvaris, G. Molnar, and M. Chahine, 2006: Accuracy of geophysical parameters derived from Atmospheric Infrared Sounder/Advanced Microwave Sounding Unit as a function of fractional cloud cover. J. Geophys. Res., 111, D09S17, doi:10.1029/2005JD006272. 